\title{
Clinical implications of the growth-suppressive effects of chlorhexidine at low and high concentrations on human gingival fibroblasts and changes in morphology
}

\author{
MARZENA WYGANOWSKA-SWIATKOWSKA ${ }^{1}$, MALGORZATA KOTWICKA ${ }^{2}$, PAULINA URBANIAK ${ }^{2}$, \\ AGNIESZKA NOWAK ${ }^{3}$, EWA SKRZYPCZAK-JANKUN ${ }^{4}$ and JERZY JANKUN ${ }^{4}$
}

\author{
${ }^{1}$ Department of Conservative Dentistry and Periodontology, Poznan University of Medical Sciences, 60-812 Poznan; \\ ${ }^{2}$ Department of Cell Biology, Poznan University of Medical Sciences, 60-806 Poznan; ${ }^{3}$ Department of Biochemistry \\ and Biotechnology, Poznan University of Life Sciences, 60-632 Poznan, Poland; ${ }^{4}$ Urology Research Center, \\ Department of Urology, College of Medicine, University of Toledo, Toledo, OH 43614, USA
}

Received January 8, 2016; Accepted April 6, 2016

DOI: $10.3892 / \mathrm{ijmm} .2016 .2550$

\begin{abstract}
Chlorhexidine (CHX) is considered the gold standard in the antiseptic treatment of the oral cavity, due to its high antibactericidal capability. With the use of CHX mouth-rinse formulations, the bacteriostatic effects are maintained by the adsorption and prolonged release of $\mathrm{CHX}$ from oral surfaces. It was believed that antiplaque formation ability and the lack of systemic toxicity of CHX render it an excellent antiseptic in post-surgical dental treatment. However, recent studies have demonstrated that $\mathrm{CHX}$ exerts cytotoxic effects on human periodontal tissues, such as gingival fibroblasts and other cells. It also reduces gingival fibroblast adhesion to fibronectin and prevents fibroblast attachment to root surfaces, thus interfering with periodontal regeneration. In this study, using human gingival fibroblasts (HGFs), we investigated effects of $\mathrm{CHX}$ on the growth, morphology and proliferation of HGFs. We found that a low concentration $(0.002 \%)$ of $\mathrm{CHX}$ does not interfere with the proliferation and morphology of HGFs. However, a higher concentration $(\geq 0.04 \%)$ of $\mathrm{CHX}$ inhibits cell proliferation and to a certain extent, affects cell morphology in a time-dependent manner. A decrease in the percentage of cells in the $G_{0} / G_{1}$ phase and the accumulation of cells in the $S$ phase following treatment with $\mathrm{CHX}$ also occurred in a dose-dependent manner. We thus concluded that $\mathrm{CHX}$ only at the concentration of $0.002 \%$ does not interfere with HGF growth, that is so critical to wound
\end{abstract}

Correspondence to: Dr Marzena Wyganowska-Swiatkowska, Department of Conservative Dentistry and Periodontology, Collegium Stomatologicum, Poznan University of Medical Sciences, 70 Bukowska Street, 60-812 Poznan, Poland

E-mail: marzena.wyganowska@periona.pl

Professor Jerzy Jankun, Urology Research Center, Department of Urology, College of Medicine, University of Toledo, 3000 Arlington Avenue, Toledo, OH 43614, USA

E-mail: jerzy.jankun@utoledo.edu

Key words: chlorhexidine, toxicity, gingival fibroblasts healing. Thus, the application of $\mathrm{CHX}$ in the post-surgical antiseptic treatment of the oral cavity should be limited.

\section{Introduction}

Chlorhexidine (CHX) is considered the gold standard in the antiseptic treatment of the oral cavity, due to its high antibactericidal capability $(1,2)$, its inhibitory effects on glycosidic and proteolytic (3) and matrix metalloproteinase activities (4), and its reducing effecfts on the leucocyte concentration (to basal levels) and on pro-inflamatory cytokines (5). CHX is an antimicrobial agent that belongs to the group of $\mathrm{N}^{5}$ derivatives of 1:6-bis-biguanidohexane $(6,7)$ and is also effective in the treatment of non-bacterial oral infections. CHX binds to negatively charged sites on the bacterial surface wall through electrostatic forces. Such an interaction affects the membrane structure and causes the leakage of intracellular bacterial components $(1,8,9)$.

With the use of CHX mouth-rinse formulations, there is an immediate bactericidal effect due to cytoplasmic precipitation. The bacteriostatic effect is further induced by the adsorption and prolonged release of CHX from oral surfaces $(1,10)$. This antiplaque formation effect and lack of systemic toxicity (5) render $\mathrm{CHX}$ a commonly used antiseptic in post-surgical dental treatment. However, recent studies have demonstrated that $\mathrm{CHX}$ exerts potent cytotoxic effects on human periodontal tissues, such as gingival fibroblasts $(11,12)$, gingival epithelial cells (13), periodontal ligament cells (14), cultured alveolar bone cell (15) and on osteoblastic cells (7). It also reduces gingival fibroblast adhesion to fibronectin (16) and prevents fibroblast attachment to root surfaces; thus, it can interfere with periodontal treatment and regeneration (7). Yet it is difficult to compare all the published results, as they refer to the different commercial mouth rinsing fluids containing $\mathrm{CHX}$, each one containing different concentrations of this active chemical agent. Some of these mouth rinsing fluids also contain alcohol, which can influence cell proliferation and morphology.

Our previous study indicated that an alcohol concentration of $10 \%$ does not inhibit fibroblast proliferation and the presence of alcohol in mouth rinsing fluids containing $0.10 \% \mathrm{CHX}$ has no 
deleterious effects on healing capacity (17). On the contrary, it helps stimulate wound healing (11). In addition, the culture media used in in vitro experiments differ [fetal bovine serum (FBS) or calf bovine serum]. Usually, experiments for evaluating the cytotoxicity of antiseptics are carried out in cell culture medium containing $10 \%$ FBS, which is similar to the composition of artificial wound fluid (18); however, FBS has an attenuating effect against CHX-induced cytotoxicity (8). Although a number of studies have demonstrated the cytotoxicity of CHX $(12,13,16)$, none of the observations lasted for $>24 \mathrm{~h}$ and none of the studies used the short-cut video to demonstrate the results. Moreover, in this study, we used the PANsys3000 system to examine the effects of CHX on human gingival fibroblasts (HGFs) cultured without FBS. PANsys3000 is a highly automated cell-culture system that is used for in vitro cell culture and for the analysis of diverse cell lines in conditions similar to those observed in vivo. This system enables the culture of various cells and the usage of diverse culture media at the same time, using the cell culture conditions of choice and constant microscopic observation. Simultaneously, in our study, we applied the xCELLigance real-time cell analysis (RTCA) system as a non-invasive and label-free approach to assess cell proliferation in real-time on a cell culture level.

\section{Materials and methods}

Cell culture. All experiments were conducted using a human gingival fibroblast (HGF) cell line (reference no. P10866; Innoprot, Biscay, Spain). Gingival fibroblasts were transferred in aseptic conditions from freezing medium [Dulbecco's modified Eagle's medium (DMEM)/F12 (1:1), 10\% FBS, 10\% dimethyl sulfoxide (DMSO) (all from Gibco, Grand Island, NY, USA)], to a $90-\mathrm{mm}$ sterile petri dish (Sarstedt, Nuembrecht, Germany) containing $10 \mathrm{ml}$ of growth medium with the following composition: DMEM/F12 (1:1) medium, 10\% FBS, antibiotics (penicillin $100 \mu \mathrm{g} / \mathrm{ml}$ and streptomycin $100 \mu \mathrm{g} / \mathrm{ml}$ ) and $2 \mathrm{mmol} / \mathrm{l} \mathrm{L-glutamine} \mathrm{(all} \mathrm{from} \mathrm{Gibco).} \mathrm{The} \mathrm{cells} \mathrm{were} \mathrm{grown}$ in aseptic conditions, in an incubator at $37^{\circ} \mathrm{C}$ with $5 \% \mathrm{CO}_{2}$ and $100 \%$ humidity. The cells were cultured until $90 \%$ confluent. At this point, they were washed with phosphate-buffered saline (PBS) and trypsinized with trypsin/EDTA solution $(0.25 \%$ trypsin containing $0.01 \%$ EDTA). After 5 min of incubation, complete growth medium was added, and the cell suspension was transferred to petri dishes.

Stimulation of gingival fibroblasts with $C H X$. To evaluate the effecs of CHX on fibroblasts, the cells were grown in regular culture medium for $24 \mathrm{~h}$. The medium was then replaced with appropriate $\mathrm{CHX}$ dilutions. The practical dilution was obtained by dissolving commercially available CHX solution [Curasept ADS $220(0.2 \% \mathrm{CHX})]$ in FBS-free medium. The final dilutions of $\mathrm{CHX}$ in the FBS-free medium were as follows: $0.002,0.01,0.02,0.04$ and $0.2 \%$. The cells were stimulated with $\mathrm{CHX}$ for $15 \mathrm{~min}$ and the solutions were then replaced with regular growth medium and the cells were grown under standard conditions for $48 \mathrm{~h}$.

Analysis of cell growth and morphology. Cell growth and morphology were assayed using PANsys3000. PANsys 3000 (Systech GmbH, Augsburg, Germany) is a multi-chamber fully automated cell culture system used for in vitro experiments simulating in vivo conditions. It allows the culture of different cell types and several components simultaneously with a variety of culture conditions and continuous microscopic observations. The parameter defined as the cell index (CI) represents cell growth, measuring the relative change in electrical impedance in the presence or absence of cells in the wells. $\mathrm{CI}$ is a unitless parameter and is calculated using the following formula: $\mathrm{CI}=\left(\mathrm{Z}_{\mathrm{i}}-\mathrm{Z}_{0}\right) / 15$ where $\mathrm{Z}_{\mathrm{i}}$ is the impedance during the experiment and $Z_{0}$ is the impedance at the beginning of the experiment (19-21).

The cells were grown prior to the experiment for $24 \mathrm{~h}$ in an incubator at $37^{\circ} \mathrm{C}$ with $5 \% \mathrm{CO}_{2}$ and $90 \%$ humidity (ftp.strefa. pl, user: m.wyganowska+kdvision.eu; password: Wyga1, supplementary 1.avi). Subsequently, the growth media were removed and replaced with the appropriate $\mathrm{CHX}$ dilutions $(0.002,0.01$, $0.02,0.04$ and $0.2 \%$ ) and the cells were resuspended in $1 \mathrm{ml}$ of DMEM FBS-free medium. The control cells were treated with $1 \mathrm{ml}$ of DMEM FBS-free medium. The cells were incubated for $15 \mathrm{~min}$ at $37^{\circ} \mathrm{C}$. After the $\mathrm{CHX}$ solution was removed, the cells were rinsed with Hank's solution (Cytogen, Wetzlar, Germany) and complete growth medium was added. Further observations were conducted for the following $48 \mathrm{~h}$. Images were acquired at 10-min intervals and finally combined into a video. All of the images were acquired in the same plate region (region of interest).

Assessment of cell proliferation rate. Real-time cell analyses (xCELLigence system; Roche Applied Science, Mannheim, Germany; ACEA Biosciences, San Diego, CA, USA) were performed to determine the effects of $\mathrm{CHX}$ on gingival fibroblast proliferation. The electronic impedance of the sensor electrodes was measured to allow the monitoring and detection of physiologic changes of the cells on the electrodes. The voltage applied to the electrodes during real-time cell analysis was approximately $20 \mathrm{mV}$ root mean square. The impedance measured between electrodes in a well depends on electrode geometry, the ion concentration in the well, and whether the cells are attached to the electrodes. In the presence of cells, cells attached to the electrode sensor surfaces act as insulators, and thereby alter the local ion environment at the electrode-solution interface, leading to increased impedance. Thus, the larger the value of electrode impedance, the larger the number of cells growing on the electrodes.

During the cell proliferation measurements, the cells were passaged after reaching confluency and were trypsinized with $0.25 \%$ trypsin. After seeding $200 \mu \mathrm{l}$ of the cell suspensions into the wells $(10,000$ cells/well) of the E-plate 96 (ACEA Biosciences), the HGFs were kept in culture to obtain the CI value of approximately 2 . Subsequently, the cells were treated with the appropriate dilutions of $\mathrm{CHX}$ and released from the metallic alloy material of the electrodes and monitored every $15 \mathrm{~min}$ for $48 \mathrm{~h}$. The control plate contained cells not stimulated with $\mathrm{CHX}$, but with the replacement of the growth medium with FBS-free medium and were then cultured in complete culture medium.

Cell cycle analysis. The cells were seeded in 60-mm culture dishes at a density of $5 \times 10^{5}$ cells/dish and allowed to adhere overnight. Following 15 min of incubation with $\mathrm{CHX}$ at dilutions $(0.002,0.004,0.01,0.02,0.04$ and $0.2 \%)$, the cells were washed twice with PBS and the solutions were then replaced 


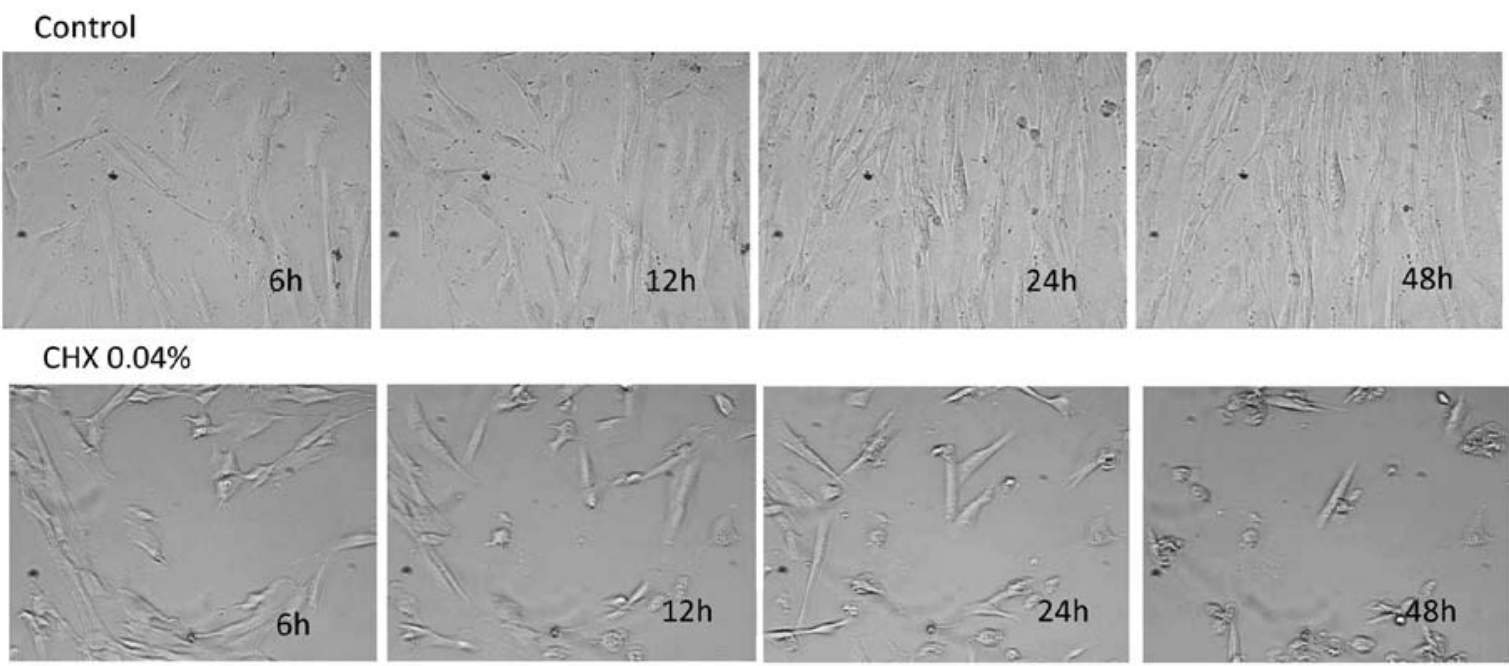

Figure 1. Representative images acquired using the PANsys3000 system showing the effects of chlorhexidine (CHX) on human gingival fibroblasts during $48 \mathrm{~h}$ of observation following stimulation. The control cells were treated with $1 \mathrm{ml}$ of DMEM FBS-free medium. The fibroblasts treated with CHX at a concentration of $0.04 \%$ were small in number, and had an oval appearance with no filopodia.

with regular growth medium, and the cells were grown under standard conditions for $48 \mathrm{~h}$. Subsequently, the cells were trypsinized (trypsin; Cytogen) and fixed with ice-cold $70 \%$ ethanol at $-20^{\circ} \mathrm{C}$ for $24 \mathrm{~h}$. Subsequently, the cells were centrifuged, washed once with PBS, and then incubated with RNAse A $(50 \mu \mathrm{g} / \mathrm{ml}$ in PBS) for $30 \mathrm{~min}$. Following centrifugation at $100 \mathrm{rpm}$ for 10 min at $4^{\circ} \mathrm{C}$, the supernatant with RNAse A was removed and intracellular DNA was labeled with $0.5 \mathrm{ml}$ of cold propidium iodide (PI) solution (0.1\% Triton X-100, $0.1 \mathrm{mM}$ EDTA, $50 \mu \mathrm{g} /$ $\mathrm{ml}$ PI in PBS) on ice for 30 min in the dark. Cell cycle distribution was measured using a FACSCalibur flow cytometer (BD Biosciences, San Jose, CA, USA). For each experiment, 10,000 cells were examined. The fluorescence of PI was excited using an argon laser $(488 \mathrm{~nm})$. The emission of red fluorescence of PI was detected in the FL3 channel $(>650 \mathrm{~nm})$ All data were collected and analyzed using CellQuest Pro software (v.5.2.1) (Becton-Dickinson, Franklin Lakes, NJ, USA). The distribution of cells in the cell cycle $\left(\mathrm{G}_{0} / \mathrm{G}_{1}, \mathrm{~S}\right.$ and $\left.\mathrm{G}_{2} / \mathrm{M}\right)$ and apoptosis were calculated using the ModFit LT program for cell cycle analysis (Verity Software House Inc., Topsham, ME, USA).

Statistical analysis. Statistical analysis was performed using Statistica v.10 (StatSoft, Inc., Tulsa, UK). The Shapiro-Wilk test was used for the normality test of continuous variables. The mean \pm standard deviation was used to describe the results of the experiments. The parametric test one-way ANOVA with the multiple comparison Tukey's post-test were applied. A value of $\mathrm{P}<0.05$ was considered to indicate a statistically significant difference.

\section{Results}

Cell growth and morphology. In the control group, fibroblast morphology did not vary significantly during the duration of the experiment. During the $48 \mathrm{~h}$ of culture after DMEM stimulation, the gingival fibroblasts formed a confluent layer with lamellipodia and spreading of the cellular matrix (Fig. 1, top panel) (ftp.strefa. pl, user: m.wyganowska+kdvision.eu; password: Wygal, supplementary 2.avi). Morphologically, no significant difference was observed between the control cells and the CHX 0.002\%-stimulated cells. Both groups exhibited a characteristic spindle-shaped fibroblast morphology. In the cells stimulated with $\mathrm{CHX}$ at the concentration of 0.01 and $0.02 \%$, a decrease in cell proliferation and a decrease in the number of cell divisions were noted (ftp.strefa.pl, user: m.wyganowska+kdvision.eu; password: Wyga1, supplementary 3.avi). There were no significant changes observed in the morphology of the fibroblasts between both groups. In the cells stimulated with $\mathrm{CHX}$ at the concentration of either 0.04 or $0.2 \%$, a progressive inhibition of cell growth and division was observed (ftp.strefa.pl, user: m.wyganowska+kdvision.eu; password: Wygal, supplementary 4.avi). The growth inhibition was accompanied by the appearance of the small round-shaped cells (Fig. 1, bottom panel).

Cell proliferation rate. Cell proliferation assays were performed using the xCELLigence system. After seeding the HGFs into the wells, the mean impedance change $(n=5)$ was measured. Impedance was recorded every $15 \mathrm{~min}$. To improve the clarity of the presentation of the results, only 4 post-CHX stimulation read-outs were analyzed: at 12, 24, 36 and $48 \mathrm{~h}$. No stimulated HGFs obtained a CI value of approximately 2 after $24 \mathrm{~h}$ of culture (Fig. 2). The control cells (treated with DMEM FBS-free medium) exhibited a significant increase in the cell index, which at $12 \mathrm{~h}$ after stimulation attained a value of $1.5 \pm 0.5$ and increased to $2.6 \pm 0.6$ after $48 \mathrm{~h}$ of incubation $(\mathrm{p}=0.003)$. The anti-proliferative concentration- and time-dependent effects of CHX on the HGFs are shown in Fig. 3. The cells stimulated with $\mathrm{CHX}$ at the concentration of $0.002 \%$ exhibited a significant increase in the CI value at $48 \mathrm{~h}(\mathrm{p}<0.05)$, albeit significantly lower $(p<0.05)$ than the control group. At higher CHX concentrations, the effects were less pronounced at the concentration of $0.01 \%$, almost leveled off at the concentration of $0.02 \%$, and were reversed at the concentrations of 0.04 and $0.2 \%$, with insignificant increase in CI values ( $p>0.05$ ) at the concentrations of 0.02 and $0.04 \%$ observed at $24 \mathrm{~h}$ as shown in Fig. 3.

Cell cycle analysis. Flow cytometry was used to examine the changes in the cell cycle of the HGFs that were either not stimu- 


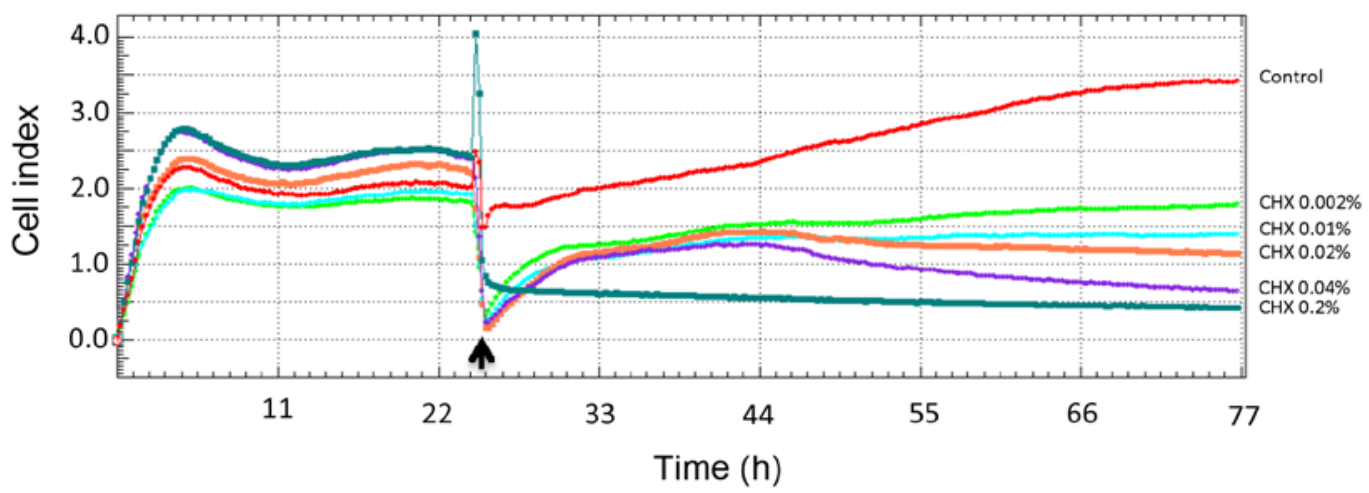

Figure 2. Real-time, label-free monitoring of the effects of chlorhexidine (CHX) on human gingival fibroblat proliferation using the xCELLigance system. A representative graph is shown. Human gingival fibroblasts were treated with various concentrations of CHX. The cell index value was monitored continuously for $48 \mathrm{~h}$ following stimulation with CHX (black arrow indicates the time of CHX administration).

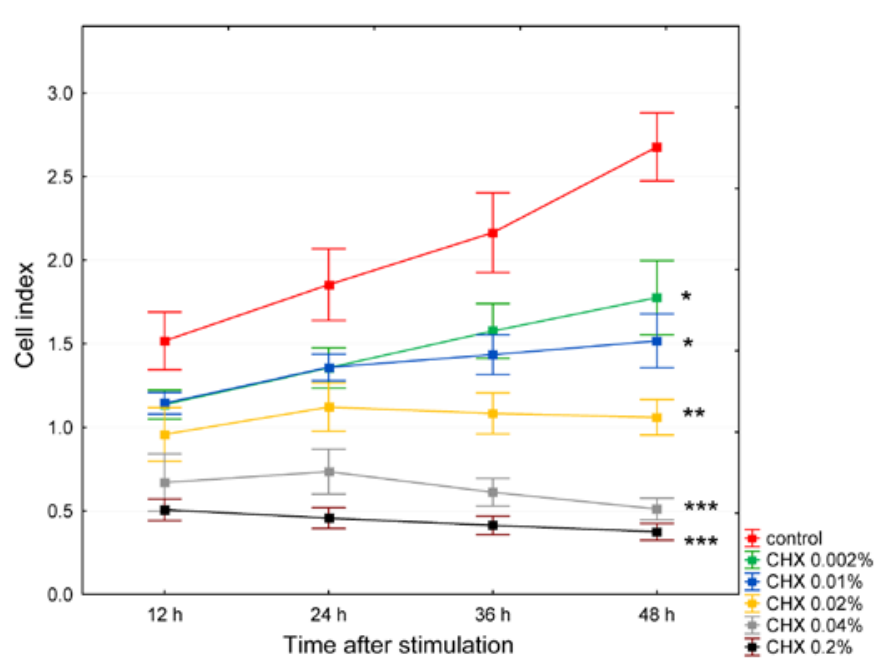

Figure 3. Concentration- and time-dependent inhibition of human gingival fibroblast proliferation following treatment with chlorhexidine at various concentrations; the results are presented as the means \pm standard deviation. ${ }^{*} \mathrm{P}<0.05,{ }^{* *} \mathrm{P}<.001$ and ${ }^{* * *} \mathrm{P}<0.0001$

lated, or stimulated with CHX. The separation of the cells into apoptotic and the $\mathrm{G}_{0} / \mathrm{G}_{1}, \mathrm{~S}$ or $\mathrm{G}_{2} / \mathrm{M}$ phases was based upon linear fluorescence intensity after staining with PI. Representative profiles are shown in Fig. 4A. A decrease in the percentage of cells in the $G_{0} / G_{1}$ phase and a buildup of cells in the $S$ phase was observed. This process was concentration-dependent. The HGFs not stimulated with CHX had $91.5 \pm 2.5 \%$ of cells in the $\mathrm{G}_{0} / \mathrm{G}_{1}$ phase, whereas the cells stimulated with $0.002,0.01,0.02$, 0.04 or $0.2 \%$ CHX had $88.0 \pm 3.7,85.4 \pm 2.4,80.9 \pm 1.1,79.4 \pm 5.7$ and $65.1 \pm 2.7 \%$ of cells in the $\mathrm{G}_{0} / \mathrm{G}_{1}$ phase, respectively (Fig. $4 \mathrm{~B}$ ). In the control group, the percentage of cells in the $S$ phase was $2.8 \pm 0.7 \%$. Following stimulation with $\mathrm{CHX}$, a concentration-dependent increase in the percentage of cells in the $\mathrm{S}$ phase was observed; the cells stimulated with the highest concentration of CHX had $22.1 \pm 1.3 \%$ of cells in the S phase (Fig. 4B). No apoptosis was observed either in the unstimulated or in the cells stimulated with 0.002 or $0.01 \%$ CHX. With the increasing CHX concentration, a significant enhancement in the percentage of cells undergoing apoptosis was detected, with the highest concentration corresponding to $9.0 \pm 2.6 \%$ of apoptotic cells (Fig. 4B).

\section{Discussion}

CHX has been widely utilized as a wound antiseptic and oral antimicrobial rinse. There have been numerous reports on its safety as an oral rinse; however, its effects on wound healing have been contradictory. It has been suggested that the direct application of CHX during regenerative periodontal therapy could have severe toxic effects on gingival fibroblasts, endothelial cells and alveolar osteoblasts, thus negatively interfering with the early healing phase (7).

In a previous study using an infected animal wound healing model with the polymer drug delivery system of PDGF, the use of hydrophilic protein promoting healing and CHX, a hydrophobic antimicrobial agent, effectively inhibited the proliferation of bacteria without exhibiting cytotoxicity to mammalian cells (22). However, CHX has been shown to induce an inflammatory reaction (23), tissue necrosis (24), and to retard the granulation of tissue formation and wound healing (25). Some other studies have established that CHX inhibits cell growth, proliferation and collagen synthesis in human osteoblasts $(7,26)$ and human alveolar bone cells $(15)$.

The comparison of the results from studies on the effects of CHX on periodontal tissue is complicated and practically impossible due to the different research methodologies applied by different authors; in particular, the duration of cell exposure, the CHX concentrations and the media used. Therefore, the most important aim of this study was to use the methods (PANsys 3000, xCELLigence) that allow us to observe the effects of CHX on cell lines in conditions similar to those observed in vivo and in real-time, and to deliver the most reliable results.

For this purpose, all experiments were conducted without medium containing fetal bovine, which is usually used for the similarity to the artificial wound fluid. It has been indicated that FBS has an attenuating effect against CHX-induced cytotoxicity, which results in a higher cell survival rate (8).

There are a number of different suggestions in the literature $(1,7,24,27)$ for the duration of cell exposure to CHX during in vitro experiments. Due to the slow release of CHX from the tooth surface and soft tissue following application, it maintains its antimicrobial activity in the oral cavity for extended periods. During this time, the oral tissues are exposed to progressively lower concentrations of CHX. Furthermore, the periodontal pocket is a specific environment 

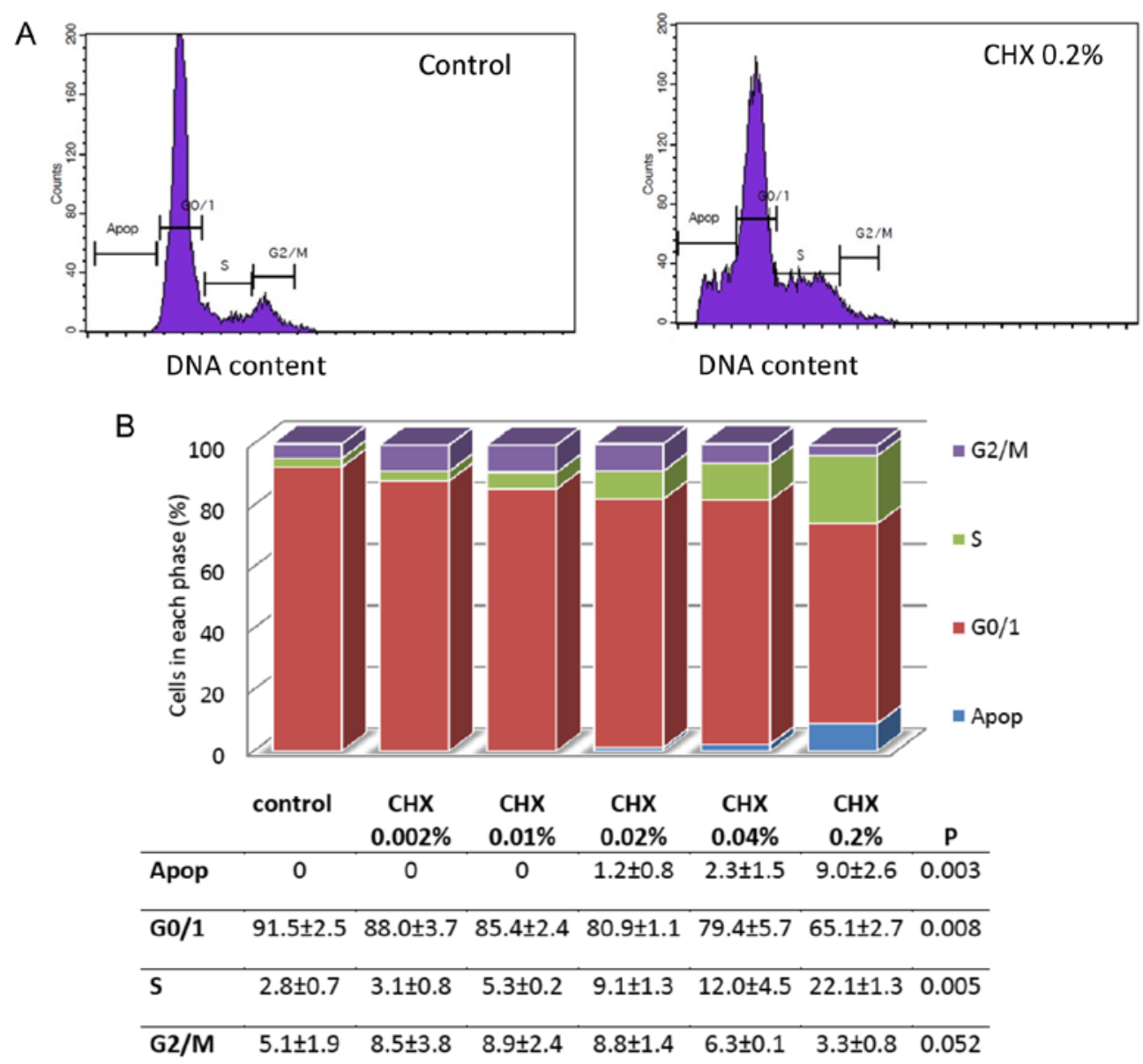

Figure 4. Flow cytometry-based cell cycle analysis of human gingival fibroblasts treated with chlorhexidine. (A) Representative histogram of DNA content for controls vs. chlorhexidine (CHX; 0.2\%)-stimulated cells. (B) A significant decline in the percentage of $\mathrm{G}_{1}$ and $\mathrm{G}_{2} / \mathrm{M}$ cells was observed, along with a considerable augmentation in the percentage of apoptotic and $\mathrm{S}$ phase cells.

in which the gingival crevicular fluid is replaced approximately 40 times/h (28) and is usually penetrated by mouth rinse only to approximately $4 \%$ of its depth during mouth rinsing. Therefore, we decided to expose gingival fibroblasts to a $\mathrm{CHX}$ dilution for longer periods of time than the standard time of oral rinsing, but shorter than the expected release time from soft tissue.

In this study, during the constant microscopic observation of cell morphology and growth in conditions similar to those observed in vivo, we observed that either cell morphology or growth did not exhibit any changes in comparison with the control group following stimulation with $0.002 \% \mathrm{CHX}$. In the cells stimulated with $\mathrm{CHX}$ at the concentrations of 0.01 and $0.02 \%$ a decrease in both the dynamics of cell proliferation and the number of cell divisions was noted, although only in the final hours of observation. There were no significant changes observed in fibroblast morphology between these two groups. In the cells stimulated with 0.04 or $0.2 \% \mathrm{CHX}$, the progressive inhibition of growth and cell division was observed, which was most significant at $32 \mathrm{~h}$ with $\mathrm{CHX}$ at $0.04 \%$, and at $16 \mathrm{~h}$ with $\mathrm{CHX}$ at $0.2 \%$. At these time points, only small roundshaped cells were observed. These results are different from the ones presented in the literature. Giannelli et al (7) used the concentration of CHX similar to ours; however, following longterm treatment (5 and $15 \mathrm{~min}$ ), the authors observed massive cell death with any concentration used (using the calorimetric method and confocal microscopy). The results were established $4 \mathrm{~h}$ after exposure. Even following short-term treatment $(1 \mathrm{~min})$ with higher concentrations of $\mathrm{CHX}(0.03-0.12 \%)$ a significant reduction in cell viability was observed.

The only comparable results of fibroblast morphology were achieved for fibroblast stimulated with $0.002 \% \mathrm{CHX}$, even if the time of exposure differed. In our study it was after 15 min of treatment, after 1 min of treatment in the study by Giannelli et al (7), $24 \mathrm{~h}$ in the study by Dogan et al (1) and $1 \mathrm{~h}$ in the study by Pucher and Daniel (27). Faria et al (25), using $\mathrm{CHX}$ at the concentration of $0.001 \%$ observed many morphological changes in the fibroblasts, and the cells were completely destroyed from the concentration of $0.004 \%$. These effects were observed using a scanning electron microscope directly following short-term stimulation. The discrepancies between these results may be due to the heterogeneity of human and animal (murine) fibroblasts, and the different investigation methods used in the different studies $(1,27)$.

On the other hand, in the study by Ros-Llor and LopezJornet (29), they did not report any genotoxic effects against oral mucosa cells resulting from mouth rinse containing CHX. The study evaluated DNA damage, cytokinetic defects, proliferative potential and cell death caused by the frequent use of triclosan, $\mathrm{CHX}$ and essential oils in ethanol solutions. No 
nuclear abnormalities in exfoliated cells, collected from cheeks with a cytobrush, were observed (29).

Our data concur with those obtained by other authors $(1,12,30)$, and confirmed the anti-proliferative effects of $\mathrm{CHX}$ on HGFs in in vitro conditions. The in vitro cytotoxicity of $\mathrm{CHX}$ occurred in a concentration and time-dependent manner. Moreover, Mariotti and Rumpf (12) postulated that CHX, in concentrations which have little effect on cellular proliferation, can significantly reduce both collagen and non-collagen protein production by HGFs in vitro.

In this study, we used the RTCA technique (xCELLigance RTCA system) to provide real-time data concerning the way that $\mathrm{CHX}$ alters the behavior of fibroblasts. The xCELLigance RTCA platform is highly accurate for monitoring cell behavior and it correlates very well with conventional adhesion, proliferation and migration assays. This non-invasive and label-free platform is being used as a robust system to measure the toxicological response to nanoparticles and novel compounds $(31,32)$. Having exposed the HGFs to $\mathrm{CHX}$, we were able to demonstrate a significant decrease in CI, which correlated with a decrease in cell proliferation.

Due to the fact that the xCELLigance system is an impedance-based platform, the changes in the CI value can also be interpreted as morphological changes in the cells. The decrease in the $\mathrm{CI}$ value associated with the highest $\mathrm{CHX}$ concentrations used could result from both the diminished cell proliferation rate and cell morphological changes, namely the decrease in the number of cell divisions and the appearance of small roundshaped cells.

Many cytotoxic agents modulate the intricate balance between cell proliferation and cell death (33). Cell death occurs through a spectrum of morphological and biochemical pathways culminating in apoptosis, necrosis or autophagy. Reduced viability often results from diminished cell proliferation or cell cycle arrest. The suggested mechanisms underlying CHX-induced cytotoxicity are connected with the inhibition of collagen synthesis $(12,26)$, the inhibition of protein synthesis $(14,27)$ or the induction of reactive oxygen species (ROS) (34). Faria et al $(24,25)$ found that only at the concentration of $0.00025 \% \mathrm{CHX}$ there was no sign of apoptosis and necrosis. The increase in the number of apoptotic cells was concentration-dependent, but starting from $0.004 \% \mathrm{CHX}$ there was no difference compared with the control group. The higher concentration of $\mathrm{CHX}$ induced cell necrosis. Chang et al (14) used 5\% CHX and indicated that it was cytotoxic to periodontal ligament cells at the concentration of $0.0001 \%$ or greater, and inhibited protein synthesis at the $0.005 \%$ concentration. The protein synthesis was almost completely inhibited by the concentration of $>0.05 \%$, as was the mitochondrial activity of the human periodontal ligament cells, which was completely inhibited by $0.125 \% \mathrm{CHX}$. CHX may also induce cell death by apoptosis and necrosis via endoplasmic reticulum stress (25). Based on studies conducted on human osteoblastic and murine endothelial cells and fibroblasts, Gianelli et al (7) suggested that CHX exerts toxic through the induction of apoptotic and auto/ necrotic cell death and involves the reduction of mitochondrial membrane potential, an increase in intracellular $\mathrm{Ca}^{2+}$ levels and oxidative stress.

Our results suggest that $\mathrm{CHX}$ induced cell cycle arrest at the $S$ phase. Both the number of cells at the $G_{0} / G_{1}$ and $G_{2} / M$ phase decreased, while the number of cells at the $S$ phase increased.
Hidalgo et al (8) observed that CHX exerted an inhibitory concentration-dependent effect on DNA synthesis from the concentration as low as $0.0001 \%$ in dermal fibroblasts. In this study, the changes in the cell cycle were observed at the concentration of $0.04 \%$ (minimum). Looking at this discrepancy, one can speculate that $\mathrm{CHX}$ exhibits a different degree of cytotoxicity towards different cell types. However, this difference may also be due to the different times of cell exposure to CHX. Hidalgo et al (8) incubated cells with $\mathrm{CHX}$ for 3, 6, 8 and $24 \mathrm{~h}$, whereas we incubated the cells with CHX for $15 \mathrm{~min}$. These could also be reasons for differences in DNA synthesis observed in our study. Hidalgo et al (8) used 5-bromodeoxyuridine (BrdU), a thymidine analogue that is incorporated into the cells during the DNA synthetic phase of replicating cells (during the $\mathrm{S}$ phase of the cell cycle). They observed a significant decrease in BRdU incorporation that occurred at the concentration of $0.0001 \% \mathrm{CHX}$, which reflects the decrease in the number of cells in the $\mathrm{S}$ phase. We observed the concentration-dependent accumulation of cells in the $S$ phase together with a decrease of cells in the $G_{2} / M$ phase following stimulation with $C H X$, which indicates that these cells do not seem to re-enter the cell cycle. It cannot be excluded that $\mathrm{CHX}$ is able to modify cell culture conditions so that quiescent $\mathrm{S}$ phase cells appear. Thus, the accumulation of inactive cells in the $S$ phase would accompany the decreasing frequency of BrdU-positive cells. However, further research is warranted to confirm these findings.

Cell cycle arrest is often followed by resumed entry into the cell cycle or cell demise via apoptosis. Our results suggest that cells were arrested in the $\mathrm{S}$ phase to repair the $\mathrm{CHX}$-induced DNA damage, and that some of the damage was not repaired causing the cells to undergo apoptosis.

In our study, we did not detect any apoptotic symptoms in the CHX-stimulated cells at the concentration below $0.01 \%$. The percentage of apoptotic cells increased to $9.0 \%$ of cells at the highest concentration. The number of apoptotic cells was assessed based on the percentage of sub-G1 ( $<2$ N DNA) fraction in HGFs, the internucleosomal DNA fragmentation being one of the hallmarks of apoptosis. As DNA oligomers are extracted during cell staining, apoptotic cells can be identified on DNA content frequency histograms, as cells with fractional sub-G1 DNA content. However, the sub-G1 DNA content cannot be used as the sole marker of apoptotic cells, as DNA fragmentation to the oligo- or mono-nucleosomal-size fragments does not always take place during apoptosis (35).

To summarize, in conditions similar to those observed in vivo, the low $\mathrm{CHX}$ concentration has a different effect on gingival fibroblasts than the high concentration. However, even this low concentration has a greater influence on cells than the untreated controls. The low $\mathrm{CHX}$ concentration has minimal cytotoxicity, as it decreases proliferation without inducing morphological changes and apoptosis.

These findings suggest a different clinical protocol for patients with improper oral hygiene and patients after surgical treatment. The low CHX concentration can have antimicrobial activity and does not influence wound healing. It was found that $0.004 \% \mathrm{CHX}$ in toothpaste inhibits bacterial colonization and growth on an enamel surface; however, even this low concentration of $\mathrm{CHX}$ was higher than the minimal concentration needed for the elimination of Streptoccocus mutans (36). The minimal inhibitory concentration (MIC) of CHX on periodontal 
pathogens is $0.0012 \%$. In addition, the penetration of CHX into the biofilm seems to be easier at lower concentrations. The compact matrix inhibits the diffusion of solutes, such as CHX into the biofilm. It is possible that conformational changes in biofilm structure, such as the opening up of the water channel, could assist in the diffusion of CHX into deeper layers. It was observed after using CHX at the concentration of $0.05 \%$, but not at the concentration of $0.2 \%$ (37). Our previous clinical study also confirmed the effectiveness of a low CHX concentration $(0.04 \%)$ in he subgingival irrigation in patients treated for chronic periodontal disease (38).

In conclusion, the aim of this study was to evaluate the effects of different concentrations of CHX on HGFs. The low concentration $(0.002 \%)$ of CHX does not interfere with the proliferation and morphology of gingival fibroblasts. The higher concentration $(\geq 0.04 \%)$ of $\mathrm{CHX}$ inhibits cell proliferation and, to a certain extent, affects cell morphology. Thus, the application of CHX in the post-surgical antiseptic treatment of the oral cavity should be limited.

\section{Acknowledgements}

This study was supported by the Poznan University of Medical Sciences research grant (no. 50201-044105190-06466).

\section{References}

1. Dogan S, Günay H, Leyhausen G and Geurtsen W: Effects of low-concentrated chlorhexidine on growth of Streptococcus sobrinus and primary human gingival fibroblasts. Clin Oral Investig 7: 212-216, 2003

2. Salem AM, Adams D, Newman HN and Rawle LW: Antimicrobial properties of 2 aliphatic amines and chlorhexidine in vitro and in saliva. J Clin Periodontol 14: 44-47, 1987.

3. Beighton D, Decker J and Homer KA: Effects of chlorhexidine on proteolytic and glycosidic enzyme activities of dental plaque bacteria. J Clin Periodontol 18: 85-89, 1991.

4. Gendron R, Grenier D, Sorsa T and Mayrand D: Inhibition of the activities of matrix metalloproteinases 2,8 , and 9 by chlorhexidine. Clin Diagn Lab Immunol 6: 437-439, 1999.

5. Houri-Haddad Y, Halabi A and Soskolne WA: Inflammatory response to chlorhexidine, minocycline $\mathrm{HCl}$ and doxycycline $\mathrm{HCl}$ in an in vivo mouse model. J Clin Periodontol 35: 783-788, 2008.

6. Cronan CA, Potempa J, Travis J and Mayo JA: Inhibition of Porphyromonas gingivalis proteinases (gingipains) by chlorhexidine: Synergistic effect of $\mathrm{Zn}(\mathrm{II})$. Oral Microbiol Immunol 21: 212-217, 2006.

7. Gianelli M, Chellini F, Margheri M, Tonelli P and Tani A: Effect of chlorohexidine digluconate on different cell types: A molecular and ultrastructural investigation. Toxicol In Vitro 2: 308-317, 2008

8. Hidalgo E and Dominguez C: Mechanisms underlying chlorhexidine-induced cytotoxicity. Toxicol In Vitro 15: 271-276, 2001.

9. Koontongkaew S and Jitpukdeebodintra S: Interaction of chlorhexidine with cytoplasmic membranes of Streptococcus mutans GS-5. Caries Res 29: 413-417, 1995.

10. Bonesvol P: Oral pharmacology of chlorohexidine. J Clin Periodontol 4: 49-65, 1997.

11. Boisnic S, Ben Slama L, Branchet-Gumila MC, Watts M and d'Arros G: Wound healing effect of Eludril in a model of human gingival mucosa. Rev Stomatol Chir Maxillofac 107: 431-435, 2006 (In French).

12. Mariotti AJ and Rumpf DA: Chlorhexidine-induced changes to human gingival fibroblast collagen and non-collagen protein production. J Periodontol 70: 1443-1448, 1999.

13. Babich H, Wurzburger BJ, Rubin YL, Sinensky MC and Blau L: An in vitro study on the cytotoxicity of chlorhexidine digluconate to human gingival cells. Cell Biol Toxicol 11: 79-88, 1995.

14. Chang YC, Huang FM, Tai KW and Chou MY: The effect of sodium hypochlorite and chlorhexidine on cultured human periodontal ligament cells. Oral Surg Oral Med Oral Pathol Oral Radiol Endod 92: 446-450, 2001.
15. Cabral CT and Fernandes MH: In vitro comparison of chlorhexidine and povidone-iodine on the long-term proliferation and functional activity of human alveolar bone cells. Clin Oral Investig 11: 155-164, 2007.

16. Cline NV and Layman DL: The effects of chlorhexidine on the attachment and growth of cultured human periodontal cells. J Periodontol 63: 598-602, 1992.

17. Wyganowska-Swiatkowska M, Urbaniak P, Szkaradkiewicz A, Jankun J and Kotwicka M: Effects of chlorhexidine, essential oils and herbal medicines (Salvia, Chamomile, Calendule) on human fibroblast in vitro. Cent Eur J Immunol (In Press).

18. Campbell KE, Keast D, Woodbury G and Houghton P: Wear time in two hydrocolloid dressing using a novel in-vivo model. Wounds 15: 40-48, 2003.

19. Marlina S, Shu MH, AbuBakar S and Zandi K: Development of a real-time cell analysing (RTCA) method as a fast and accurate screen for the selection of chikungunya virus replication inhibitors. Parasit Vectors 8: 579, 2015.

20. Urcan E, Haertel U, Styllou M, Hickel R, Scherthan H and Reichl FX: Real-time xCELLigence impedance analysis of the cytotoxicity of dental composite components on human gingival fibroblasts. Dent Mater 26: 51-58, 2010.

21. Xing JZ, Zhu L, Gabos S and Xie L: Microelectronic cell sensor assay for detection of cytotoxicity and prediction of acute toxicity. Toxicol In Vitro 20: 995-1004, 2006.

22. Jiang B, Zhang $G$ and Brey EM: Dual delivery of chlorhexidine and platelet-derived growth factor-BB for enhanced wound healing and infection control. Acta Biomater 9: 4976-4984, 2013.

23. Onçağ O, Hoşgör M, Hilmioğlu S, Zekioğlu O, Eronat $\mathrm{C}$ and Burhanoğlu D: Comparison of antibacterial and toxic effects of various root canal irrigants. Int Endod J 36: 423-432, 2003.

24. Faria G, Celes MR, De Rossi A, Silva LA, Silva JS and Rossi MA: Chlorhexidine-induced apoptosis or necrosis in L929 fibroblasts to cultured 1929 fibroblasts. J Endod 33: 715-722, 2007.

25. Faria G, Cardoso CR, Larson RE, Silva JS and Rossi MA: Chlorhexidine-induced apoptosis or necrosis in L929 fibroblasts: A role for endoplasmic reticulum stress. Toxicol Appl Pharmacol 234: 256-265, 2009.

26. Lee TH, Hu CC, Lee SS, Chou MY and Chang YC: Cytotoxicity of chlorhexidine on human osteoblastic cells is related to intracellular glutathione levels. Int Endod J 43: 430-435, 2010.

27. Pucher JJ and Daniel JC: The effects of chlorhexidine digluconate on human fibroblasts in vitro. J Periodontol 63: 526-532, 1992.

28. Goodson JM: Pharmacokinetic principles controlling efficacy of oral therapy. J Dent Res 68: 1625-1632, 1989.

29. Ros-Llor I and Lopez-Jornet P: Cytogenetic analysis of oral mucosa cells, induced by chlorhexidine, essential oils in ethanolic solution and triclosan mouthwashes. Environ Res 132: 140-145, 2014.

30. Tsourounakis I, Palaiologou-Gallis AA, Stoute D, Maney P and Lallier TE: Effect of essential oil and chlorhexidine mouthwashes on gingival fibroblast survival and migration. J Periodontol 84: 1211-1220, 2013.

31. Ramis G, Martínez-Alarcón L, Quereda JJ, Mendonça L, Majado MJ, Gomez-Coelho K, Mrowiec A,Herrero-Medrano JM, Abellaneda JM, Pallares FJ, et al: Optimization of cytotoxicity assay by real-time, impedance-based cell analysis. Biomed Microdevices 15: 985-995, 2013.

32. Quereda JJ, Martínez-Alarcón L, Mendoça L, Majado MJ, Herrero-Medrano JM, Pallarés FJ, Ríos A, Ramírez P, Muñoz A and Ramis G: Validation of xCELLigence real-time cell analyzer to assess compatibility in xenotransplantation with pig-to-baboon model. Transplant Proc 42: 3239-3243, 2010.

33. Müller G and Kramer A: Biocompatibility index of antiseptic agents by parallel assessment of antimicrobial activity and cellular cytotoxicity. J Antimicrob Chemother 61: 1281-1287, 2008.

34. Yeung SY, Huang CS, Chan CP, Lin CP, Lin HN, Lee PH, Jia HW, Huang SK, Jeng JH and Chang MC: Antioxidant and pro-oxidant properties of chlorhexidine and its interaction with calcium hydroxide solutions. Int Endod J 40: 837-844, 2007.

35. Darzynkiewicz Z, Bedner E and Traganos F: Difficulties and pitfalls in analysis of apoptosis. Methods Cell Biol 63: 527-546, 2001.

36. Zampatti O, Roques C and Michel G: An in vitro mouth model to test antiplaque agents: Preliminary studies using a toothpaste containing chlorhexidine. Caries Res 28: 35-42, 1994.

37. Hope CK and Wilson M: Analysis of the effects of chlorhexidine on oral biofilm vitality and structure based on viability profiling and an indicator of membrane integrity. Antimicrob Agents Chemother 48: 1461-1468, 2004.

38. Wyganowska-Swiatkowska M, Jaskula J and Wieckowska B: Professional irrigation in periodontal treatment. Polish J Eviront Stud 16: 316-319, 2008. 